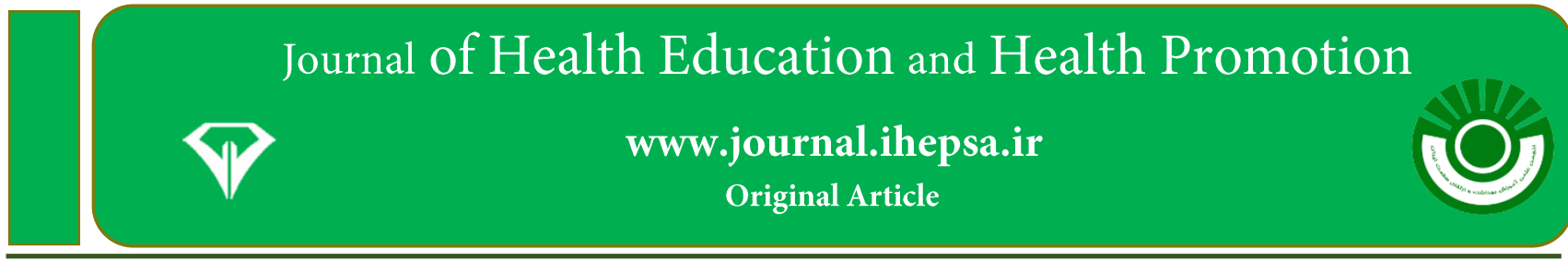

\title{
Self-Efficacy Relationship with Social Health among Nurses in Taleghani Hospital in Kermanshah
}

Ayoub Mohammadi ${ }^{1}$ Parvaneh Kheftan $^{2}$, Borzoo Amirpour ${ }^{3}$, Maryam Alsadat Sepidehdam ${ }^{4}$, Fatemeh Gholami Jam ${ }^{1}$

1. Dept. of Social Work, University of Social Welfare and Rehabilitation Sciences, Tehran, Iran

2. Dept. of Social Work, University of Applied Sciences, Shahid Foundation for the Affair, Kermanshah, Iran

3. Dept. of Psychology, Payame Noor University, Tehran, Iran

4. Dept. of Counseling and guidance, Kermanshah University of Medical Sciences, Kermanshah, Iran

\section{Article Information}

\section{Article History:}

Received: 2017/09/11

Accepted: 2018/01/17

Available online: 2018/01/30

IJHEHP 2018; 6(1):072-079

DOI:

10.30699/acadpub.ijhehp.6.1.72

Corresponding Author:

Parvaneh Kheftan

Dept. of Social Work, University of

Applied Sciences, Shahid

Foundation for the Affair,

Kermanshah, Iran

Tel: 09187311829

Email:

pkhftan2015@gmail.com

Use your device to scan and read the article online

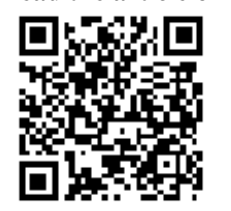

\section{Abstract}

Background and Objective: Health is a multi-dimensional concept, and the WHO has pointed to its four physical, psychological, spiritual and social dimensions. Social health is one of the most important health indicators of each country and can be influenced by different factors. The purpose of this study was to investigate the relationship between self-efficacy and dimensions of nurses' social health.

Methods: The research method was descriptive-analytic, correlation type. The statistical population was working nurses in Taleghani Hospital in Kermanshah in 2016. A sample of 100 were selected using randomized sampling method. Data were collected using the Demographic Information Questionnaire, Keyez methodology, and Sherer Self-efficacy Questionnaire. Data were entered into Spss-22 software and analyzed using Pearson correlation, independent t-test and one-way ANOVA.

Results: The results showed that there was a significant relationship between nurses' self-efficacy and their social health $(\mathrm{p}<0.05)$. Also, there was no significant relationship between self-efficacy with demographic variables such as age, sex, education, residence and income level ( $\mathrm{p}>0.05)$.

Conclusion: This research shows that there is a meaningful relationship between self-efficacy of the population studied and their social health. However, through selfefficacy-based interventions and education, the nurses' social health status was promoted.

KeyWords: Nurses, Self-Efficacy, Social Health

Copyright @ 2018 Journal of Health Education and Health Promotion. All rights reserved.

How to cite this article:

Mohammadi A, Kheftan P, Amirpour B, Sepidehdam M A, Gholami Jam F. Self-efficacy Relationship With Social Health among Nurses in Taleghani Hospital in Kermanshah. Iran J Health Educ Health Promot. 2018; 6 (1) :72-79

Mohammadi, A., Kheftan, P., Amirpour, B., Sepidehdam, M, A., Gholami, Jam, F.(2018). Selfefficacy Relationship With Social Health among Nurses in Taleghani Hospital in Kermanshah. Iranian Journal of Health Education and Health Promotion, 6(1):72-79 
رابطؤ خود كار آملى با سلامت اجتماعى بين :برستاران بيمارستان طالقانى كرمانشاه

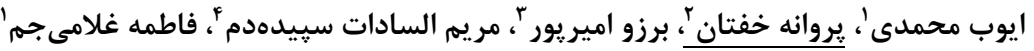

ا. ا. كروه مددكارى اجتماعى، دانشكاه علوم بهزيستى و توانبخشى، تهران، ايران

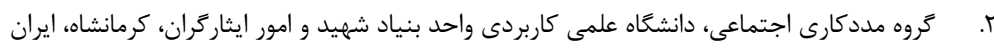

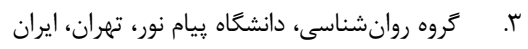

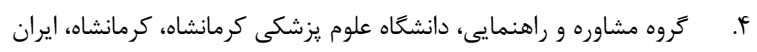

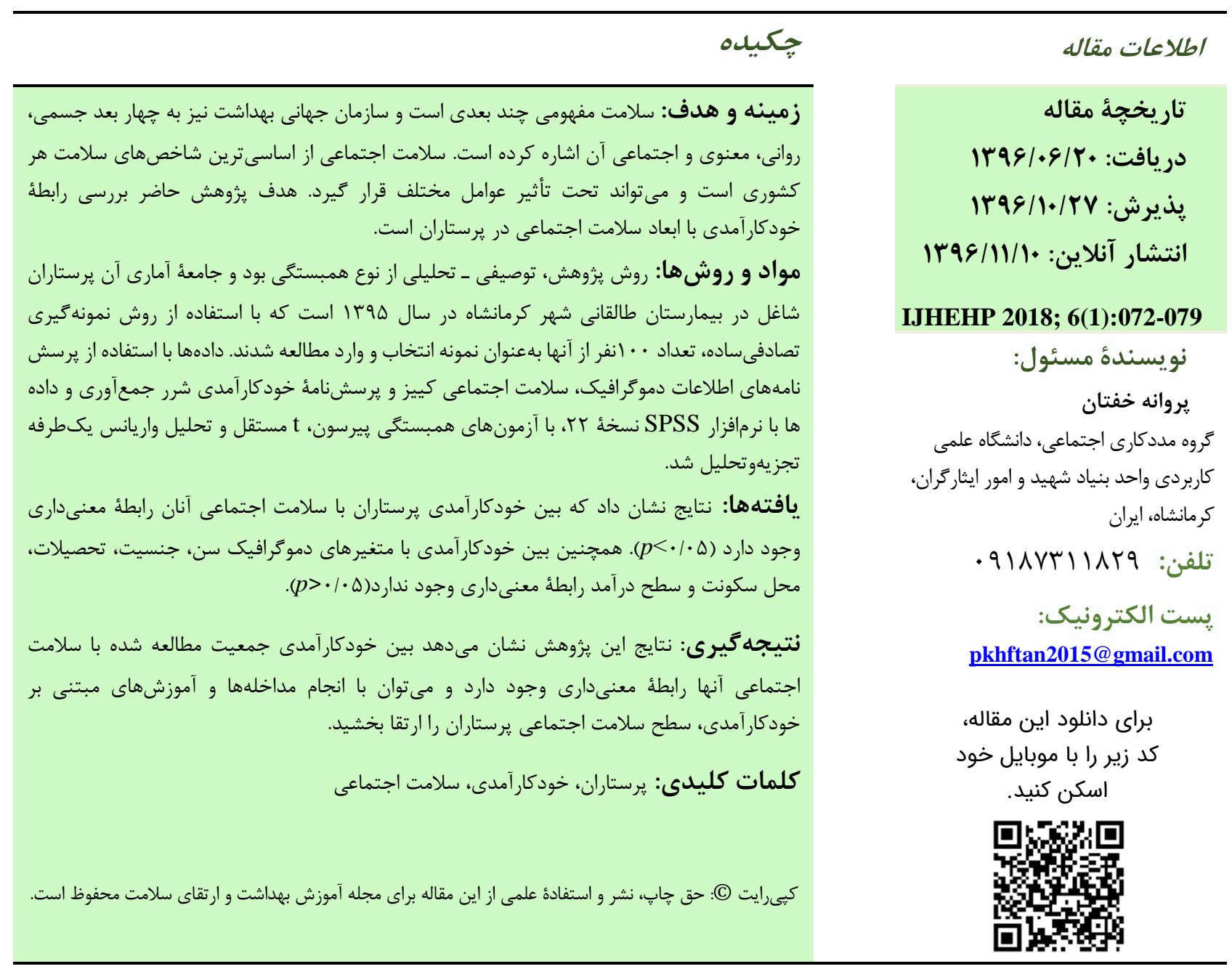

مقلمهه

داشته و از عوامل گوناگونى تأثير مىيذيرند (؟). در موضوع سلامت، به ابعاد جسمانى و فيزيكى سلامت بيشتر توجه شده ولى به ابعاد روانى و اجتماعي آن كمتر توجه ميى شود (r). سازمان جهانى بهداشت در به راستاى تامين سلامت روانى، جسمانى و اجتماعى اعضاى جامعه به كشورهاى عضو
سلامت بنيادىترين عنوانى است كه حيات انسان به آن استوار است. سلامت شرط ضرورى ايفاى نقشهاى اجتماعى است (1) سلامتى ابعاد مختلف جسمانى، روانى،

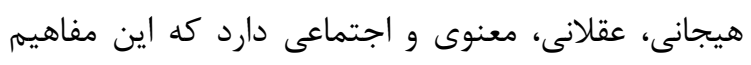
ضمن بهرهمندى از وجوه مشترك، جنبههاى متفاوتى نيز 
جسمى و روانى در تماس بوده و ممكن است بدين سبب در ابعاد مختلف سلامت در معرض خطر ابتلا به مشكلات

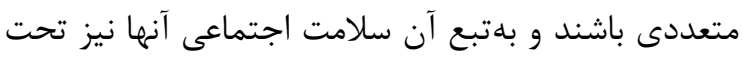

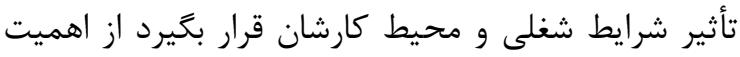
بسزايى برخوردارند. بلنوعى مى توان كفت كه سطح سلامت فيط فيط

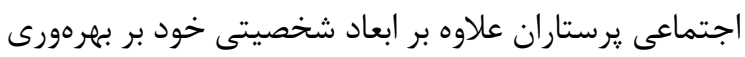

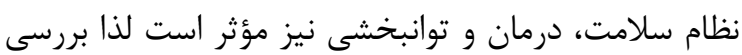
سطح سلامت اجتماعى در ميان اين قشر لازم و ضرورى به نظر مىرسد. طبق نظرئُ سلامت، هر فرد در صورتى سالم تلقى مىشود كه سطح بالايى ازسلامت اجتماعى داشته

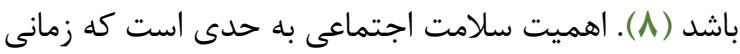
شخصى را واجد سلامت اجتماعى مى دانند كه بتوانند فعاليت ها و نقش اجتماعى خود را در حد متعارف بروز و ظهور دهد (•(، 9). يزوهشها حاكى از آن هستند كه برخى عوامل،

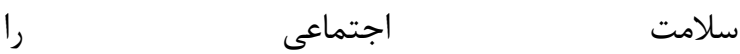
تحتتأثير قرار مىدهند. برخى از اين عوامل عبارتاند از: وضعيت اقتصادى ـ اجتماعى، سطح تحصيلات، سن، ميزان دريافت حمايت اجتماعى و وضعيت تأهل (1).يكى از عوامل احتمالىاى كه گمان مىرود بر سطح سلامت اجتماعى افراد

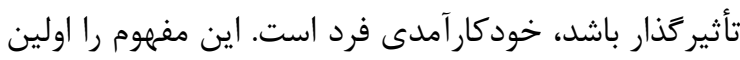
بار Albert Bandura در سال 19VV مطرح كرد. خودكارآمدى را باور به ظرفيتهاى شخصى در راستاى شناسايى و بهكارگيرى مجموعهاى از اعمال ضرورى براى برى دستيابى به اهداف مدنظر تعريف كردهاست (rا). گمان بر آن است كه هرجه ميزان خودكارآمدى شخص بالاتر باشد يعنى به توانايىها و ظرفيتهاى خويش اعتماد و باور

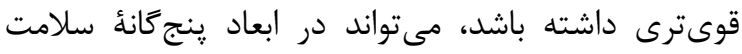
اجتماعى (شكوفايى اجتماعى، همبستگى اجتماعى، انسجام

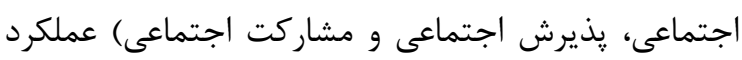

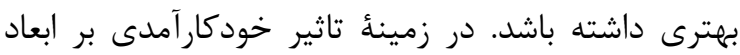

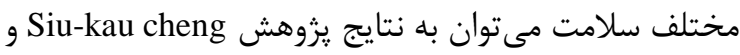
Stephen خودكارآمدى با بهبود سلامت روان رابطه دارد (I).

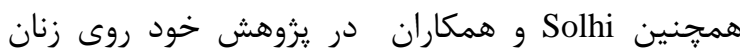
مراجعهكننده به مراكز درمانى دريافتند كه ميان سطح

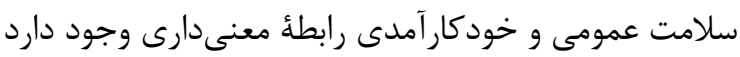
Tohidi . (IF) رابطة ميان يرستيز شغلى و سلامت اجتماعى يرستاران شهر
تاكيد كرد كه هيج كدام از ابعاد سلامت بر ديخرى برترى ندارد (F). بسيارى از افراد با مسئلة سلامت جسمى و روانى

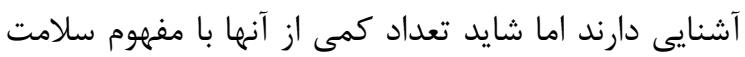

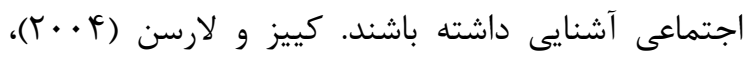
سلامت اجتماعى را ارزيابى فرد از كيفيت روابطش با خانواده،

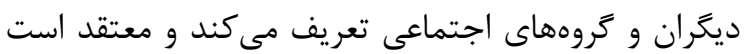

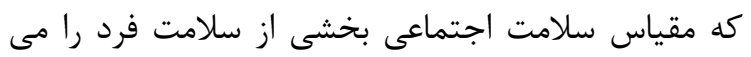

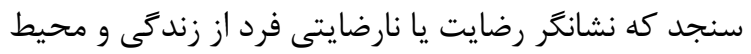
اجتماعى بوده و درواقع ياسخهاى درونى فردى را همم شامل مىشود (ه). سلامت اجتماعى عبارت است از توانائى انجام موثر و كارآمد نقشهاى اجتماعى بدون آسيب رساندن به ديخران كه ابعاد مختلفى دارد. اين ابعاد عبارت است است ازئ

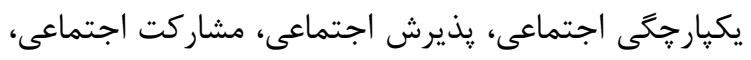

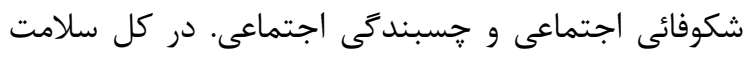
اجتماعى دربر گيرنده سطوح مهارتهاى اجتى اجتماعى و عملكرد

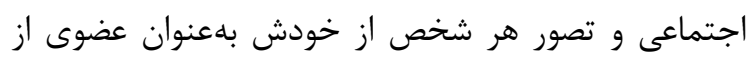

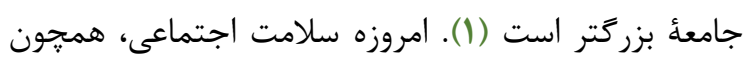

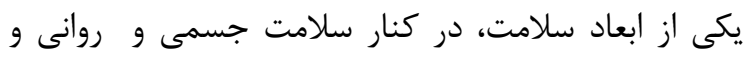

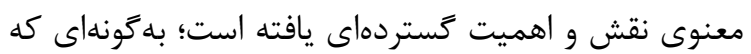
ديخر، سلامتى فقط نداشتنِ بيمارىهاى جسمى و روانى

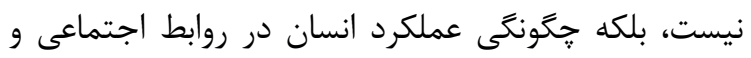
نحوه تفكر او درباره اجتماع نيز بهعنوان معيارهاى ارزيابى بـاني سلامت فرد درسطح كلان جامعه به شمار مىرود (V) را بررسى كرد. يكى از اين زمينهها، سلامت اجتماعى است كه بر جنبههاى ديگرى جون سلامت جسمى و روانى تأثير

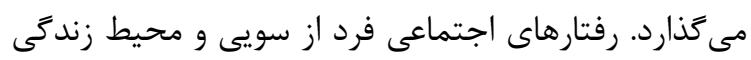

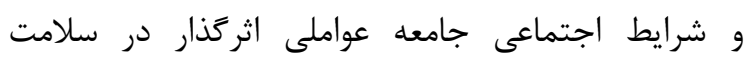

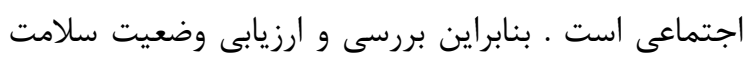

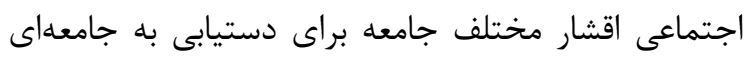

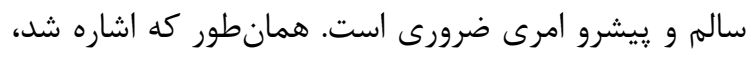

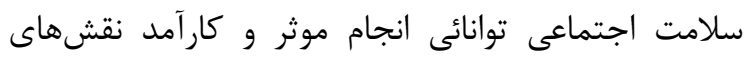
اجتماعى بدون آسيبرساندن به ديخران است، اين تعريف

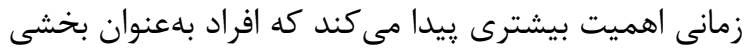

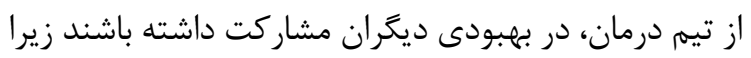

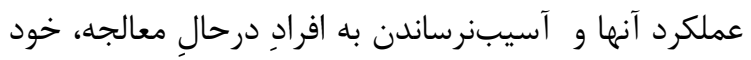
بلنوعى سلامت اجتماعى محسوب مىشود. در اين ميان

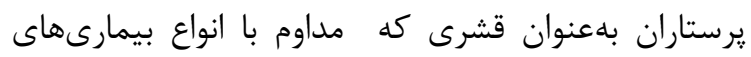




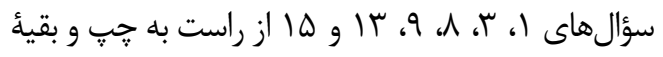

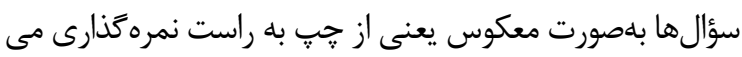

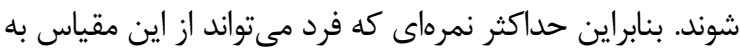

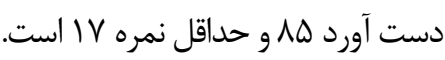

\section{يرسشنامة سلامت اجتماعى كييز (فرم كوتاه):}

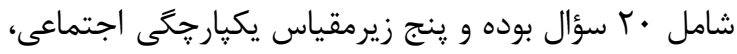

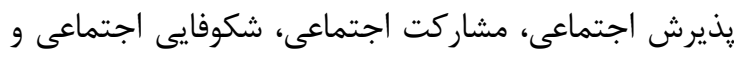

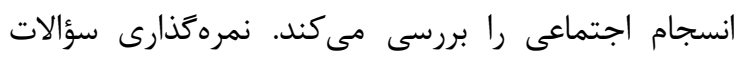
بهورت ينج كزينهاى در مقياس ليكرت است. Babapoor و

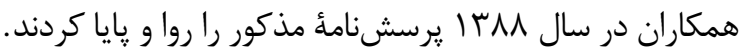

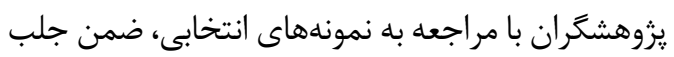

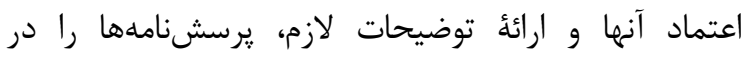

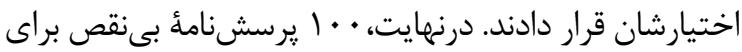

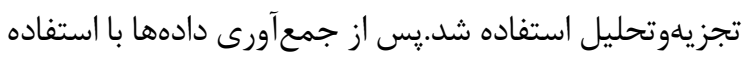

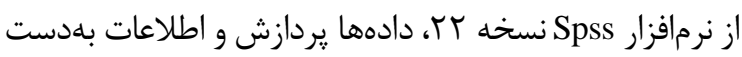
آمده با استفاده از آزمونهاى تحليل يراكنش يك طرآ طرفه

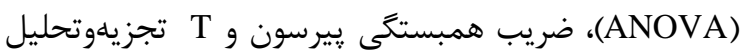
شد. همجنين براى توصيف جامعله مطالعه شده از آمارهاى توصيفى مثل ميانگين و... استفاده شد.

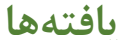

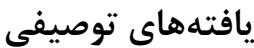

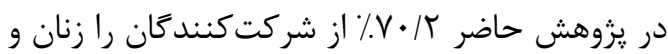
بقيه را مردان تشكيل داده بودند. ميانگَين وانحراف معيار سنى شركت كنند

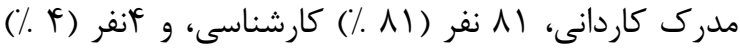

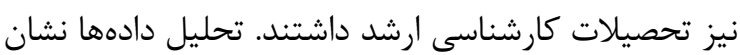

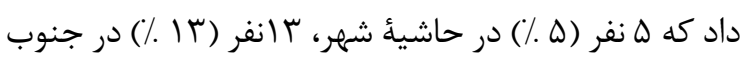

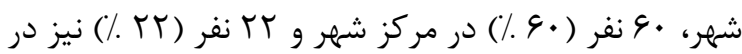

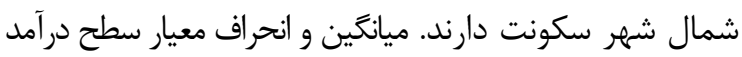

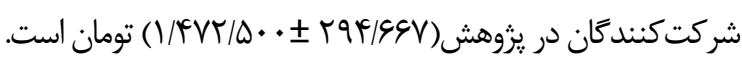

\section{يافتههاى تحليلى}

فرضيه: بين سلامت اجتماعى و خودكارآمدى رابطئ

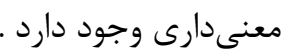

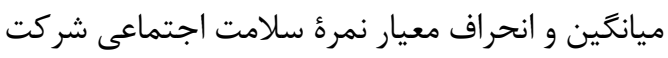
كنندكان(I/ خود كارآ آدى نشان داد كه ميانكَين و انحراف معيار نمره آنان (است. لازمبهذكر است كه با توجه به بالان
همدان يرداختند. آنها دريافتند كه ميان اين دو متغير رابطهٔ معنى دارى وجود دارد (ها). در يزوهشهاى قبلى، به رابطه احتمالى ميان سلامت اجتماعى و سطح خودكارآمدى يرستاران توجهى نشده است؛ يس با توجه به اهميت بالاى

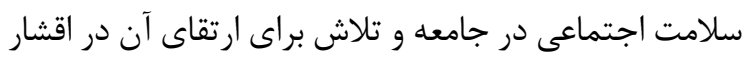
مختلف جامعه، هدف يزوهش حاضر بررسى رابطهُ سطح خودكارآمدى برستاران و ميزان سلامت اجتماعى آنها است.

$$
\text { روش بررسى }
$$

روش يزوهش، توصيفى ـ تحليلى از نوع همبستكى و

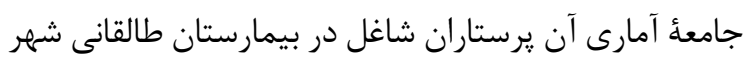

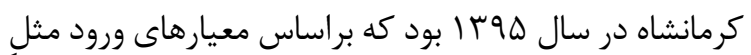

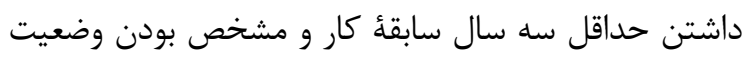

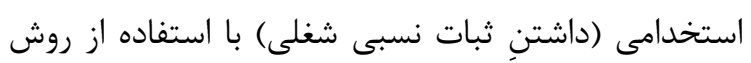
نمونه

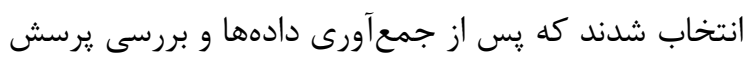

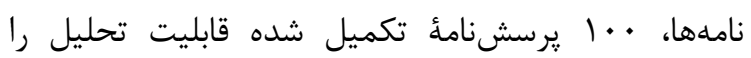

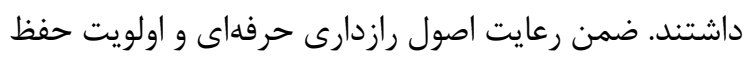

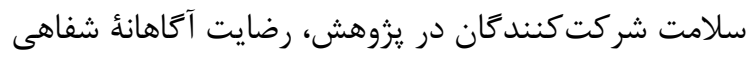

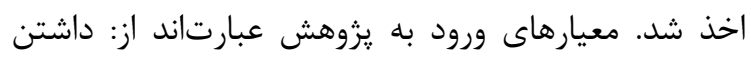
حداقل سه سال سابقه كار در بيمارستان طالقانى كرمانشاه

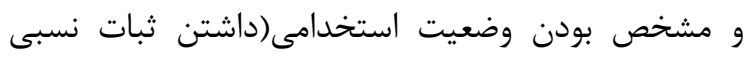

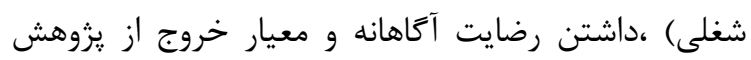

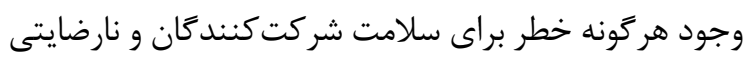

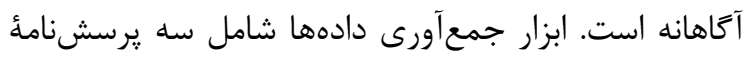

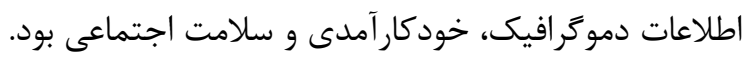

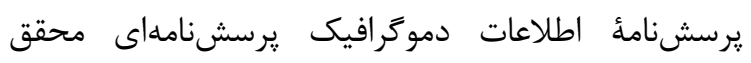
ساخته بود كه مواردى از قبيل سن، تحصيلات، جنسيت،

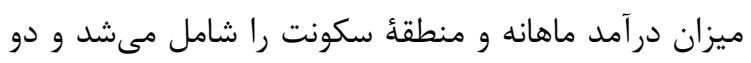

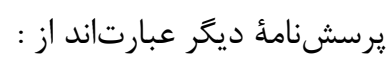

\section{الف: يرسشنامه خودكار آمدى عمومى شرر: در}

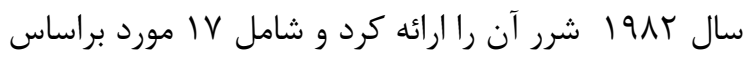

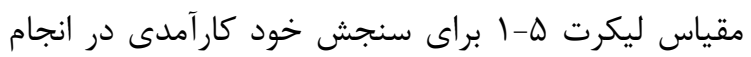

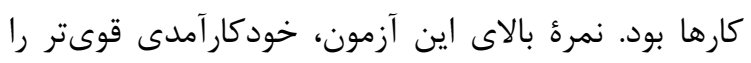

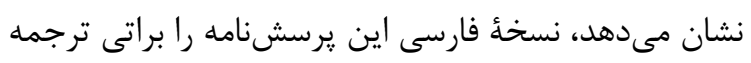

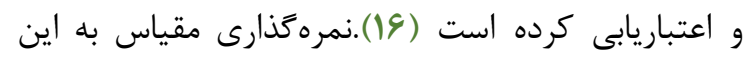
صورت است كه به هر ماده امتياز ا تا ه تعلق مى كَيرد. 
در رابطه با متغير سن و سطح درآمد، با توجه به اينكه

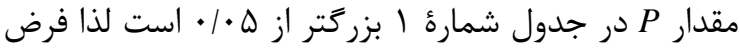

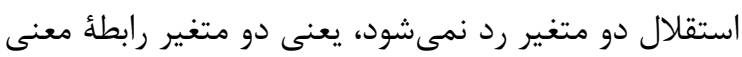

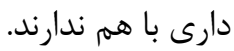

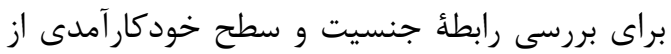

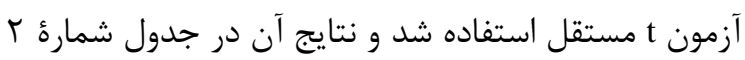

بودن حجم نمونه (•r =>> ) و استناد به قضئُ حد مركزى، متغيرهاى سلامت اجتماعى و خودكارآمدى توزيع نرمال

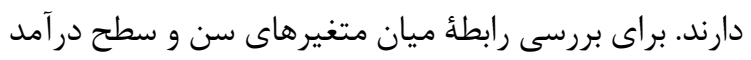

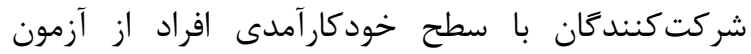

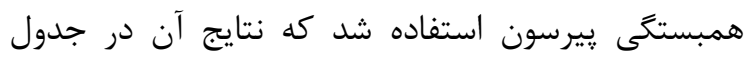
شمارها ا ذكر شده است. ذكر شده است.

جدول ا. بررسى رابطةُ ميان دو متغير سن و سطح در آمد با سطح خودكار آمدى

\begin{tabular}{|c|c|c|}
\hline مقدار P & مقدار آزمون & متغير \\
\hline$\cdot / 199$ & $-1 \cdot r q$ & سن و سطح خود كار آمدى \\
\hline$\cdot / \wedge \vee q$ & $-\cdot \cdot \cdot 1 \mathrm{~V}$ & سطح در آمد و خودكار آمدى \\
\hline
\end{tabular}

جدول r. بررسى رابطؤ ميان جنسيت و سطح خودكار آمدى

\section{مقدار}

$\cdot 19 \cdot 1$

\section{مقدار آزمون}

- /ara
متغير

جنسيت و خودكار آمدى
رابطة ميان متغيرهاى محل سكونت و سطح تحصيلات با خودكارآمدى بلهوسيله آزمون تحليل واريانس مئس

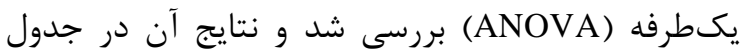
شمارؤ ب آمده است.
با توجه به اينكه مقدار p بزر عتر از ه • • • است، فرض استقلال دو متغير رد نمىشود يعنى اين دو متغير ارتباط

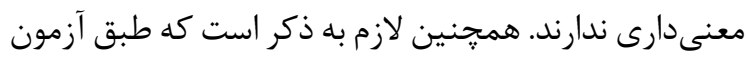
لوِن دو گروه (مرد و زن) واريانس همَّون دارند.

جدول شمارهّ. بر رسى رابطهُ ميان متغيرهاى محل سكونت و سطح تحصيلات با خودكار آمدى

\begin{tabular}{|c|c|c|}
\hline Pقدار P P & مقدار آزمون & متغير \\
\hline$\cdot / 9 \vee 1$ & $\cdot 1 \cdot \vee 9$ & محل سكونت و سطح خودكار آمدى \\
\hline$\cdot / \mu / f$ & l/lve & سطح تحصيلات و خودكار آمدى \\
\hline
\end{tabular}

رابطة احتمالى بين دو متغير خودكارآمدى و سلامت

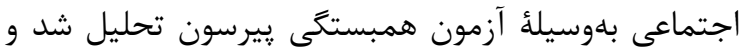
در جدول أ به نتايج آن اشاره شد.

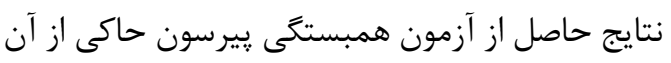

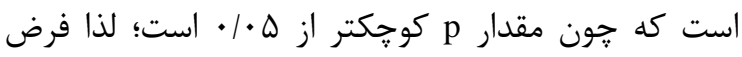
استقلال دو متغير تأييد نمىشود يعنى دو متغير ارتباط معنى دارى با هم دارند.

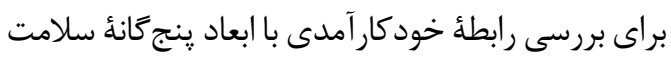
اجتماعى از آزمون همبستخى يیرسون استفاده شد كه نتايج حاصل از اين تحليل در جدول شماره ه ذذر شده است.
در رابطه با متغير محل سكونت، با توجه به اينكه مقدار

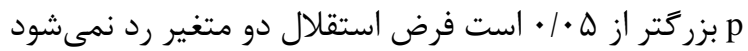
يعنى اين دو متغير ارتباط معنى دارى ندارند. همجنين لازم

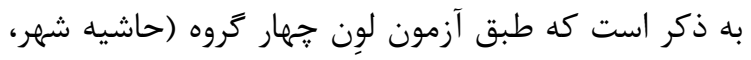
جنوب شهر، مركز شهر و شمال شهر) واريانس همغون دارند. همجنين دربارهٔ متغير سطح تحصيلات و خودكارآمدى نيز

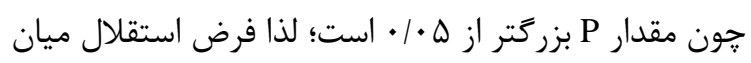

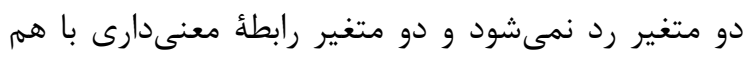

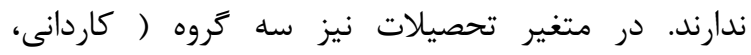
كارشناسى، كارشناسى ارشد ) واريانس همكون دارند. 
جدول F. بررسى رابطهُ ميان خودكار آمدى و سلامت اجتماعى
مقدار

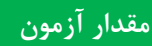
متغير

$\cdot / \cdots$

$\cdot /$ FVF

خودكار آمدى و سلامت اجتماعى

جدول شمارة هه ـ بررسى رابطهُ خود كار آمدى با ابعاد سلامت اجتماعى

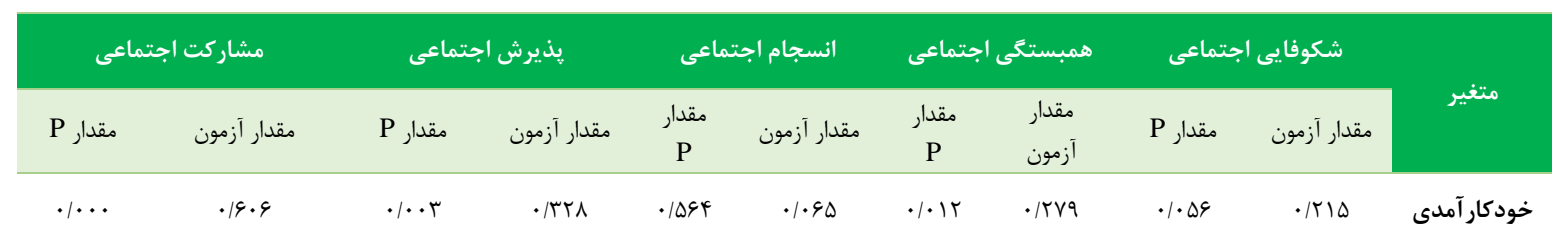

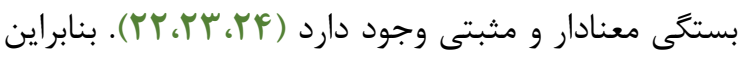

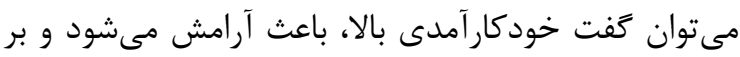

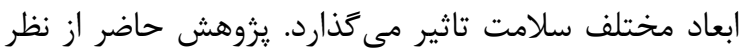

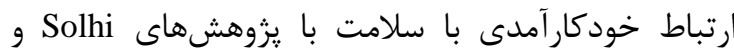

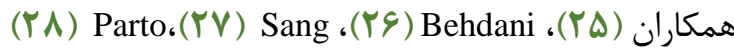

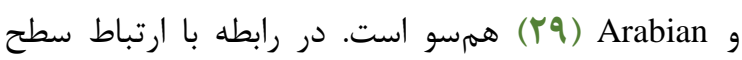

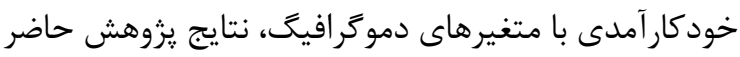

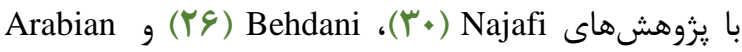

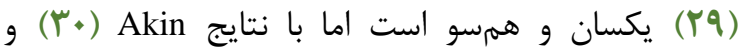
Pandey مطالعٔ ما با ساير مطالعات ذكر شده به تفاوتهاى جامعل يزوهشى مربوط مىشود.

از جمله نقاط قوت يزوهش حاضر مىتوان به بعدى از

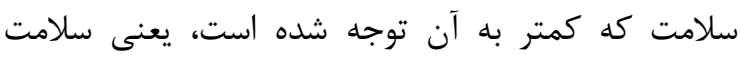

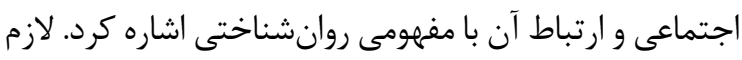
به ذكر است يزوهش حاضر نيز مثل بسيارى از يزوهش إنهاى ديكر خالى از ايراد نيست و محدوديتهايى دارد. از جمله نداضه

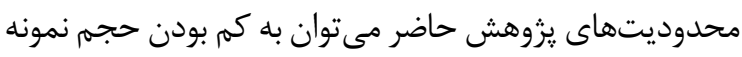

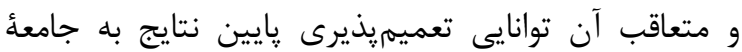
يرستاران اشاره كرد. بهمنظور تعميميذيرى بيشتر يُ بيشنهاد

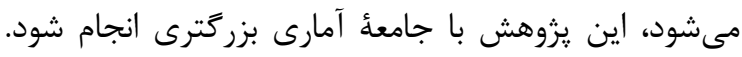

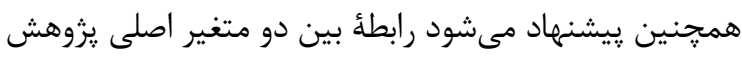
يعنى سطح خودكارآمدى و سلامت اجتماعى ميان ساير اعضاى تيم درمان بررسى و با يرستاران مقايسه شود. از

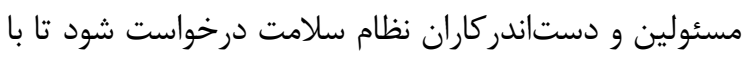
توجه به نتايج يزوهش حاضر و يزوهشهاى مشابه، مداخلاتى
با توجه به نتايج ذكر شده در جدول شماره له در رابطه با متغيرهاى شكوفايى اجتماعى و انسجام اجتماعى، جون مقدار

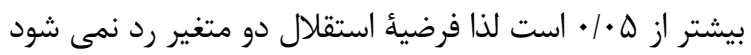

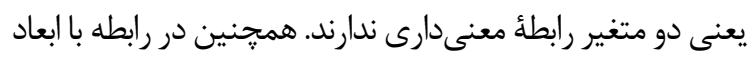

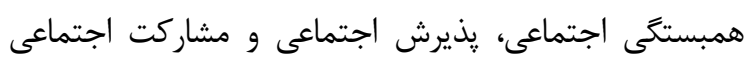

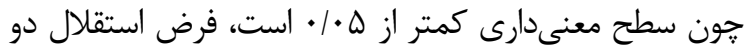

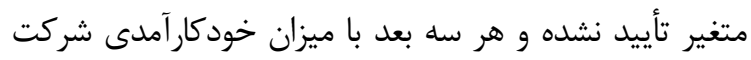

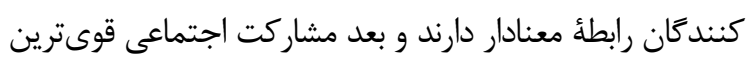
رابطه را با ميزان خودكار آمدى دارد.

\section{بح}

هدف مطالعهُ حاضر بررسى رابطؤ خود كار آمدى با ابعاد سلامت اجتماعى بين يرستاران بود. يافتههاى يزوهش حاض حاضر

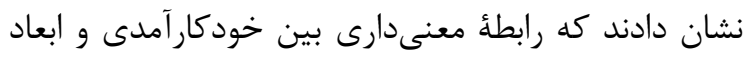
سلامت اجتماعى وجود دارد. يزوهشها نشان بـان دادين دادهاند كه باورهاى خودكارآمدى بر بسيارى از جنبه ونهاى كاردرد شخصى تأثير مى كذارند. كسانى كه درمقايسه با با ديكران

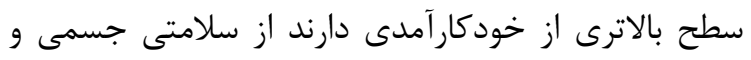

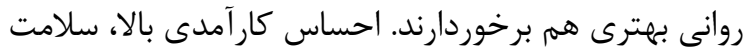

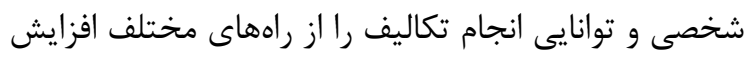

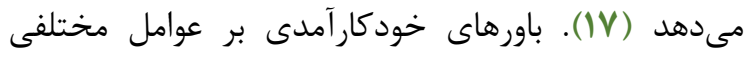

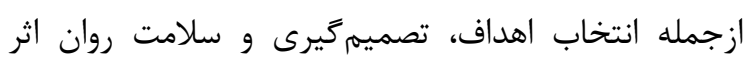

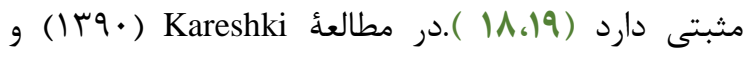
Askaryzadeh Mahani خودكارآمدى، بيشترين اثر كلى را بر سلامت فران روان

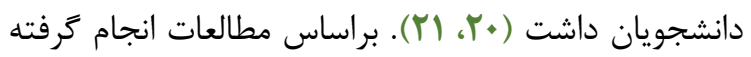
بين باورهاى خودكارآمدى افراد و سلامت معنوى آنان هم 
خودكارآمدى يرستاران انجام داد، به جهار مورد اشاره خواهد شد: ا. كسب مهارت عملى؛ ؟.كاهش استرس شغلى و فراهم

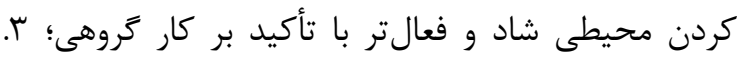
ترغيب و تشويق شفاهى مهارتهاى موجود(ارائه بازخورد

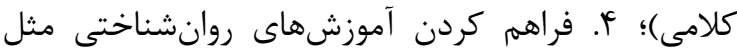
مهارت حل مسأله، كنترل استرس و خشم(مهارتهاى زندى)

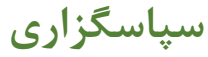

نويسندكان اين اثر بر خود لازم مىدانيد از يرستارانى كه در اين يزوهش شركت داشتهاند، تشكر و قدردانى كنند.

$$
\text { تعارض در منافع }
$$

بين نويسندگان هيجزَّه تعارض در منافع گزارش

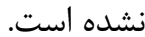

\section{References}

1. Mohseni M. Medical Sociology. 6nd end. Tehran: Tahmouri Publications;2009.

2. Wissing M, Fourie A. Spirituality as a component of psychological well-being. International Journal of Psychology. England: Psychology Press; 2000. PMC1221536

3. Segrin C, Flora J. Poor social skills are a vulnerability factor in the development of psychosocial problems. Human Communication Research. 2000;26(3):489$514 \quad$.https://doi.org/10.1111/j.1468 2958.2000.tb00766.x

4. Organization WH. Global strategy on diet, physical activity and health: a framework to monitor and evaluate implementation. 2006

5. Keyes CL, Shmotkin D, Ryff CD. Optimizing wellbeing: The empirical encounter of two traditions. Journal of personality and social psychology. 2002;82(6):1007 .https://doi.org/10.1037/0022 3514.82.6.1007 PMid:12051575

6. Raymond C, Wedding D. Current Psychotherapies.7nd end. Pacific Grove (CA): Brooks Cole; 2004

7. Samaram E. Social Health and it's indices. Collection of articles and lectures of the 1st social health congress . Ministry of Health and Medical Education Publication, 2011:68-75.

8. Graham H. Social determinants and their unequal distribution: clarifying policy understandings. Milbank Quarterly. 2004;82(1):101-24. https://doi.org/10.1111/j.0887-378X.2004.00303.x PMC2690205

9. Mitnick S, Leffler C, Hood VL, American College of Physicians Ethics P, Committee HR. Family caregivers, patients and physicians: ethical guidance to optimize relationships. J Gen Intern Med.

$$
\begin{aligned}
& \text { روانشناختى را بهمنظور ارتقاى سطح خود كار آمدى و سلامت } \\
& \text { اجتماعى يرستاران و كادر درمان طراحى و ارزيابى كنند. } \\
& \text { نتيجهَ" تئرى } \\
& \text { در اين مطالعه جنان كه ذكر شد بين سهمم مصرفى و } \\
& \text { فوايد سلامت اجتماعى نقش مهمى در تضمين يويايى و }
\end{aligned}
$$

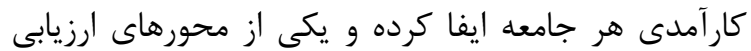

$$
\begin{aligned}
& \text { سلامتى جوامع مختلف، محسوب مىشود؛ لذا هدف تمام }
\end{aligned}
$$

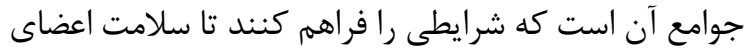

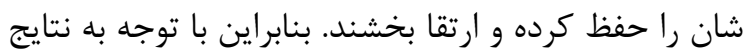

$$
\begin{aligned}
& \text { يزوهش حاضر مى توان نتيجه گَرفت كه با انجام مداخلات و }
\end{aligned}
$$

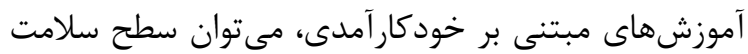

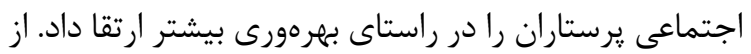

$$
\begin{aligned}
& \text { جمله فعاليتهايى كه مىتوان براى ارتقاى سطح }
\end{aligned}
$$

2010;25(3):255-60

https://doi.org/10.1007/s11606-009-1206-3 PMC2839338

10. Abbasi A, Asayesh H, Rahmani H, Shariati A, Hosseini S, Rouhi G. The burden on cargivers from hemodialysis patients and related factors. Journal of Research Development in Nursing \& Midwifery. 2011;8(1):26-33.

11. Mirowsky J, Ross CE. Social causes of psychological distress. New Jersey: Transaction Publishers; 2003. PMC140769

12. Dilorio C, Shafer PO, Letz R, Henry TR, Schomer DL, Yeager K. Behavioral, social, and affective factors associated with self-efficacy for selfmanagement among people with epilepsy. Epilepsy Behav. 2006;9(1):158-63 https://doi.org/10.1016/j.yebeh.2006.05.001 PMid:16798100

13. Cheung S-K, Sun SY. Effects of self-efficacy and social support on the mental health conditions of mutual-aid organization members. Soc Behav Pers. 2000;28(5):413-22 . https://doi.org/10.2224/sbp.2000.28.5.413

14. Solhi M, Kazemi SS, Haghni H. Relationship between general health and self-efficacy in women referred to health center No.2 in Chaloos. Razi J Med Sci. 2013; 20(109):72-9.

15. Tohidi SH, Shoorvasi M, Shayan A, Ahmadinia H, Furohari S. Development and Psychometric Relationship between Occupational Prestige and Social Health of Nursing Staff: A Cross-Sectional Study. Published by Canadian Center of Science and Education. 2016;9(3):251-9 https://doi.org/10.5539/gjhs.v9n3p25 
16. Barati BS. The simple and multiple relationships between self-effectiveness, self-discovery and selfesteem with academic performance of students in the third years of the new system in Ahvaz [MSc Thesis]. Ahvaz, Iran: Shahid Chamran University of Ahvaz. 1997.

17. Pajares F, Schunk DH. Self and self-belief in psychplpgy and education: An historical perspective.In J.Aronson \& D. Cordova psychology of education. New York: Academic press; 2002 .PMC1222310

18. Fooladvand K, Farzad V, Shahraray M, Sangari AA. Role of social support, academic stress and academic self-efficacy on mental and physical health. Contempor Psychol. 2013;4(2):81-95.

19. Fakhri Z, Rezaii A, Pakdaman SH, Ebrahimi S. Themediator role educational self-achievement in goal achievement prediction based on positive and negative emotion in adolescents. J Appl Psychol. 2013;6(1):55-68.

20. Kareshki H, Pakmehr H. Relationship between Perceived Self-efficacy, Meta-cognitive, and Critical Thinking with Mental Health among Medical Sciences Students. Hakim. 2011;14(3):180-7.

21. Askaryzadeh Mahani M, Soleimani L, Zafarnia N, Miri S. The Relationship between SelfEfficacybeliefs and Mental Health and Academic Achievement in Bam Nursing Students. J Res Dev Nurs Midwifery. 2015;12(2):29-37.

22. Adeqbola MS. Spirituality, Self-Efficacy, and Quality of Life among Adults with Sickle Cell Disease.South online J Nurs Res. 2011;11(1):5.

23. Gupta MG. Spiritual intelligence and emotion intelligence in relation to self efficacy and self regulation among college student. International journal of social sciences \&interdisciplinary research. 2012;1(2):60-9.

24. Duggleby W, Cooper D, Penz K. Hope, self-efficacy, spiritual well-being and job satisfaction. J Adv Nurs. 2009;65(11):2376-85 .https://doi.org/10.1111/j.13652648.2009.05094.x PMid:19737323

25. Solhi M, Kazemi SS, Haghni H. Relationship between general health and self-efficacy in women referred to health center No.2 in Chaloos. Razi JMed Sci. 2013;20(109):72-9.
26. Behdani S, Dastjerdi R, Sharifzadeh Gh. Relationship between trust in God and self - efficacy With mental health in type II diabetics: J Birjand Univ Med Sci. 2012;19(3):302-11.

27. Sang G, Valcke M, Van Braak J, Tondeur J. Student teachers' thinking processes and ICT integration: Predictors of prospective teaching behaviors with educational technology. Computers \& Education. 2010;54(1):103-12 .

https://doi.org/10.1016/j.compedu.2009.07.010

28. Parto M, Besharat MA. The direct and indirect effects of self- efficacy and problem solving on mentalhealth in adolescents:Assessing the role of coping strategies as mediating mechanism. Procedia - Socialand Behavioral Sciences. 2011;30:639-43 . https://doi.org/10.1016/j.sbspro.2011.10.124

29. Aerabian A, Khodapanahi M, Heidari M, Saleh Sedghpour B.The relationship between self-efficacy beliefs on mental health and educational success. J Psychol. 2004;32(8):360_71.

30. Akin S, Can G, Durna Z, Aydiner A. The quality of life and self-eficacy of Turkish breast cancer patients undergoing hemotherapy. Eur J Oncol Nurs. 2008;12(5):449-56 .

https://doi.org/10.1016/j.ejon.2008.07.006 PMid:18842460

31. Pandey M, Thomas BC, SreeRekha P, Ramdas K, Ratheesan K, Parameswaran S, et al. Quality of life determinants in women with breast cancer undergoing treatment with curative intent. World J Surg Oncol. 2005;3(1):63 .https://doi.org/10.1186/1477-7819-363 PMC1261539 